\title{
Sandy ka tail (Saara Hardwickii Oil) and Footpath Hakeems: a Challenge to Modern Clinics
}

\section{Muhammad Ehsan $^{1 *}$, Muhammad Zohaib Khalil ${ }^{2}$, Faiz Rasool ${ }^{3}$}

ISSN: 2311-8636 (Print) ISSN: 2312-2021 (Online)

Licensed:

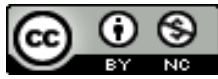

${ }^{1} \mathrm{Ph} . \mathrm{M}$ Scholar, Department of English Language and Literature, The University of Lahore, Lahore, PAKISTAN

${ }^{2}$ M.Phill Student, The University of Lahore, Lahore, PAKISTAN

${ }^{3}$ Professor, Department of Forestry, Rangeland Management and Wildlife, University of Agriculture, Faisalabad 38040, PAKISTAN

Source of Support: Nil

No Conflict of Interest: Declared

Email for correspondence: ehsanlitterateur@gmail.com

\section{ABSTRACT}

Penis enlargement, here and there called male improvement, alludes to a variety of methods planned to build the size, length, or erectile inflexibility of the human penis. Systems extend from manual activities to extending gadgets and surgical methods, with reports of triumphs and disappointments around the globe. As far back as the advancement of humanity, penis has been viewed as the most vital part of a male body which is in charge of proliferation. A solid and solid penis is coveted by each man. In the event that a man has an immature penis or on the off chance that it doesn't work legitimately while having intercourse the individual may fall into misery and despicable feeling about himself. Sanda (Saara hardwickii), commonly known as Hardwicke's spiny-tailed lizard or the Indian spiny-tailed lizard is a species of agamid lizard found patchily distributed in the Thar desert, Kutch, and surrounding arid zones in India and Pakistan.

Keywords: Sandy ka tail (Saara hardwickii), Footpath Hakeems, modern clinics

\section{INTRODUCTION}

Penis enlargement here and there called male improvement alludes to a variety of methods planned to build the size, length, or erectile inflexibility of the human penis. Systems extend from manual activities to extending gadgets and surgical methods, with reports of triumphs and disappointments around the globe. While a few strategies are known to be out and out deceptions, others can deliver some measure of progress. Frequently, in the promoting of false items, the refinement between transitory expansion, i.e. erection, and perpetual broadening is purposely muddied. The inverse system is penis diminishment. Minimal authentic logical research has been done particularly on the subject of non-surgical penile development; existing cases of critical and changeless expansion are for the most part recounted, unconfirmed by target look into, and can be one-sided the interests and feelings of the source. At present, there is no verification of any non-surgical method that forever increments either the thickness or length of a natural penis. Experimental research has been done with respect on the wellbeing and adequacy 
(or scarcity in that department) of the elements of different pharmaceutical or semipharmaceutical arrangements however, nothing has developed to bring about a standard drug to receive any of them. There are likewise hazards characteristic in a portion of the more intrusive strategies, with negative results going from the tearing of skin and scarring to changeless loss of sexual capacity. A big part of the advertising of business penisbroadening medicines depends on dubious attestations that a bigger penis improves sexual ability and general engaging quality to potential mates. Expansion of an original penis is recognized from looking for alleviation from the perceived medicinal state of micropenis, where surgery to build the organ's size is in some cases required for urinary or sexual purposes. Nervousness about the extent of one's penis might be (in extraordinary cases) a mental/psychiatric condition best managed by qualified restorative professionals.

Anatomy of human penis

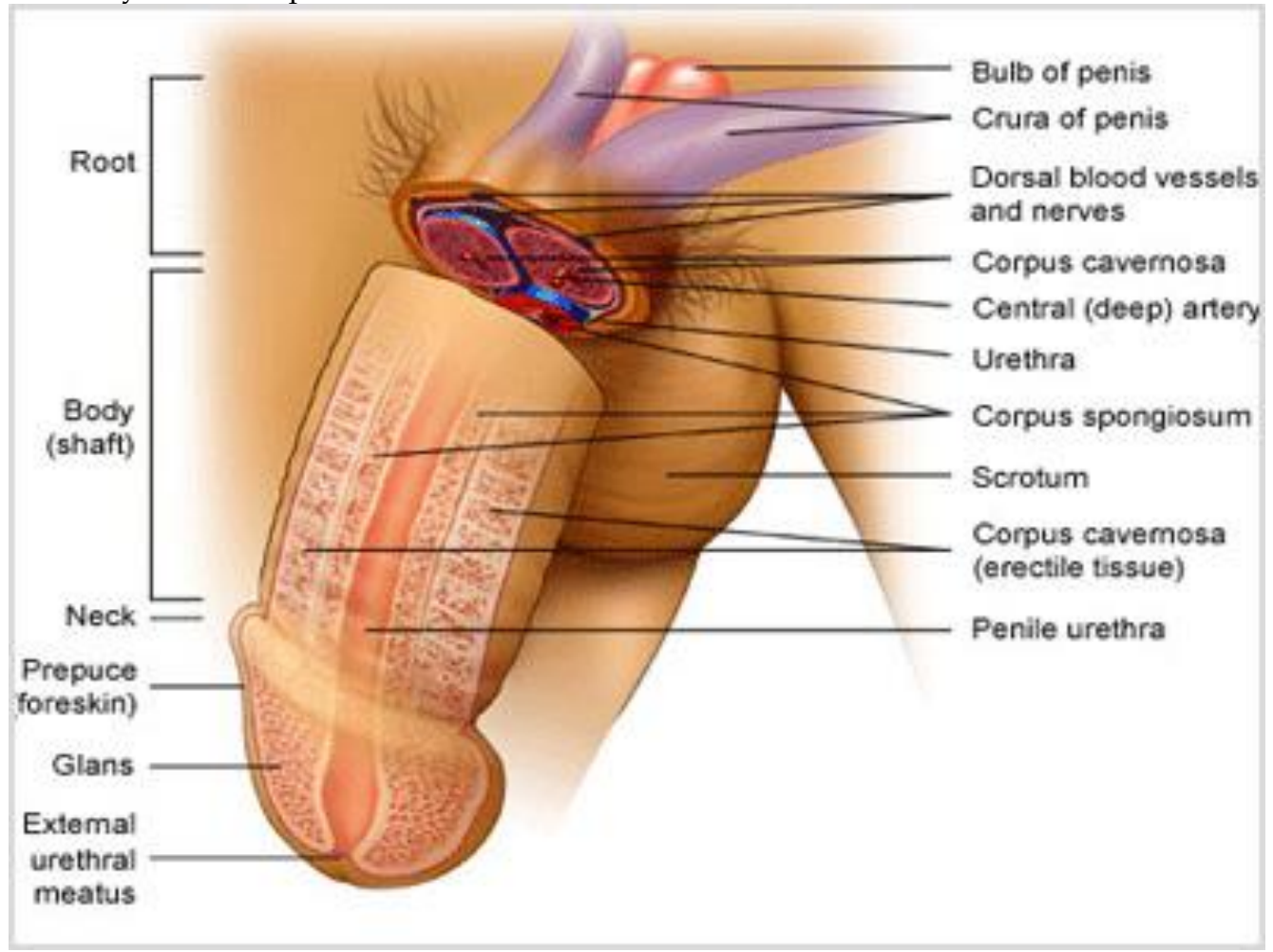

\section{Techniques used for Penis EnLARgement in the World}

\section{Surgery, Pills and Supplements}

Most men won't wish to continue to surgery when appropriately educated of the imaginable result and dangers of confusions. Systems by unlicensed specialists can prompt to genuine difficulties.

There are a few surgical medicines, all conveying a danger of the huge inconveniences. The Second International Consultation on Sexual Dysfunctions closed, Penis broadening pills, patches, and treatments are regularly offered over the Internet. While a few items contain innocuous fixings, numerous are completely untested for security and symptoms, and none of these items has been shown powerful. 


\section{PhysicAL TECHNIQUES}

An assortment of exercise based recuperation methods has been utilized as a part of an endeavor to develop the human penis. By and large, the strategies include extending, prolongation by the utilization of little weights, or expanding the blood flow as well as the circulatory strain in the penis. There is likewise the huge cover between procedures expected to amplify the penis and strategies planned to accomplish other, related targets, for example, turning around weakness, expanding the term of erections, or improving sexual peak.

\section{Penis pump}

A penis pump is a cylinder that is fitted over the penis, with a manual or mechanized pump to make an incomplete vacuum around the penis, engorging it as blood is attracted. As vacuum builds, the weight inside the veins of the penis increments also; intemperate vacuum causes vascular harm. Penis pumps might be utilized to briefly beat indications of feebleness however, don't cure the condition: a tourniquet-like ring must be connected to keep the blood caught inside the penis, generally the erection will promptly die down. Pumps may work regardless of the possibility that there is nerve or vascular harm keeping a characteristic erection, yet inordinate or delayed utilize (hours) will bring about lasting mischief as over-energetic pumping can blast veins and shape rankles. The viability of penis pumps for lasting penis amplification was analyzed by Kazem Hosseini and Alizadeh. They contemplated 37 men with penis length under $10 \mathrm{~cm}$ and found no noteworthy change in penile length after utilizing pumps for six months. The viability of vacuum treatment was around $10 \%$, and the patient fulfillment rate was $30 \%$. The finish of the paper expressed that vacuum treatment of the penis is not a compelling technique for a penile extension, but rather gives mental fulfillment to a few men.

In the US, penis pumps might be secured by Medicare on the off chance that they are regarded medicinally important. Pumps have been utilized to effectively treat men with Peyronie's ailment, which causes uncommon shortening and bend of the penis. A 31-quiet study led by the Department of Urology at St Peter's Hospitals and the Institute of Urology in London found, "clinically and measurably huge change in penile length, an edge of ebb and flow, and torment following 12 weeks of vacuum pump utilize". In this study, subjects with Peyronie's attempted two ten-minute pumping sessions every day for twelve weeks. The extra penis length, of 0.5 centimeters $(0.20 \mathrm{in})$ was a surprising symptom found in around $33 \%$ of the subjects and not a proposed point of the study.

\section{Clamping}

Clamping is an unsafe and risky technique. The objective of Clamping is to build the span of the penis utilizing a contracting gadget, for example, a shoestring, link cinch, or a tight rooster ring to confine blood stream out of the organ. The gadget is solidly joined at the base of the erect penis, and the man takes part in "edging" (expanded masturbation). A metal rooster ring is unsafe because blood caught in the penis can make evacuation of the ring outlandish without crisis intercession, for example, removal or sawing the ring off. Clipping can bring about lasting cataclysmic harm to the penis.

\section{Jelqing}

Jelqing is a physical-therapy technique, expected to accomplish "characteristic penis enlargement" by expanding pulse and flow. It is performed by over and over stroking the penis in a pressing movement from the base of the pole to the crown of the glans; gadgets have likewise been made to accomplish this same impact. The movement might be portrayed as 'draining'. 
As per an article in BJUI, the system has old Arabian causes; and an Arabic word identified with "milking" is in some cases asserted as the etymological foundation of the term, in spite of the fact that this point is questioned and the real source of the term stays vague.

While there are numerous episodic cases of progress from supporters of the strategy, there is no restorative proof for its adequacy. Besides, restorative writer Christopher Wanjek has said that the claim that the strategy will "amplify the penile holes that load with blood, having neither rhyme nor reason organically." Similarly, Sue Johanson clarifies Jelqing can't work in any way, shape or form grow the penis. However, it is probably not going to bring about any genuine harm. Albeit considered more secure than numerous other, more "radical" systems for penis-augmentation, Jelqing could bring about vein tearing, scar arrangement, torment, deformation, and desensitization of the penis if done mistakenly.

\section{Traction}

Traction is a nonsurgical strategy to stretch the penis is by utilizing gadgets that draw at the glans of the penis for amplified timeframes. Starting 2013, the dominant part of research examines the utilization of penile Traction concentrates on treating the ebb and flow and shrinkage of the penis as an aftereffect of Peyronie's malady, albeit some writing exists on the effect on men with short penises Traction as a penis-augmentation technique originates from the perception that tissues under persistent strain will experience cell duplication. The outcome is tissue extension, bringing about a changeless increment of the tissue. Numerous types of body alteration utilize this standard. Whether successful or not, over the top strain can bring about harm to the tissues or nerves of the penis.

The 2013 meta-examination by Doctors Chung and Brock reasons that numerous present studies indicate promising confirmation for little to direct lasting penis stretching by footing and in spite of the cases of numerous producers, no proof of progress in penis circumference. Chung and Brock additionally highlight the trouble in controlling such studies, the absence of an arbitrary determination of patients, and the potential for choice predisposition because of the high necessities of patient congruity and inspiration. Cutting Edge thinks about have not yet decided the ideal time or footing power, the change in penis expansion among patients utilizing comparative time or constrain, or how persistently patients must use the footing gadget to pick up results.

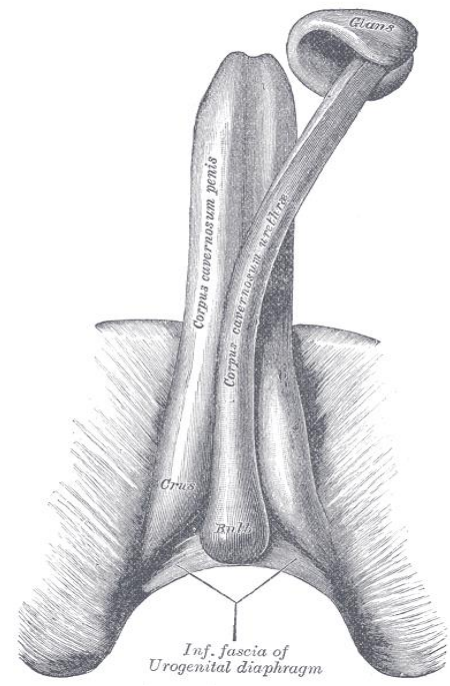




\section{OUTCOMES OF THESE TECHNIQUES}

In Vietnam, numerous Vietnamese men endeavored self-penis growth by injecting liquid silicone into their penises, and in this manner experienced inconveniences, for example, contaminations, putrefaction, tumors, swelling, and different distortions, losing the capacity to engage in sexual relations, and must be hospitalized.

\section{DoES AYURVEDA HAVE A DRUG FOR PENIS AUGMENTATION?}

The antiquated Indian therapeutic records demonstrate that there are numerous herbs and characteristic components which are useful in expanding the extent of a penis. The late progressed looks into have additionally uncovered this. This as well as demonstrated that these herbs likewise increment the general sexual execution by numerous folds. So normal penis enlargement is a win circumstance for each one.

\section{How PEOPLE ARE ATtRacted by FoOtPath HAKEemS}

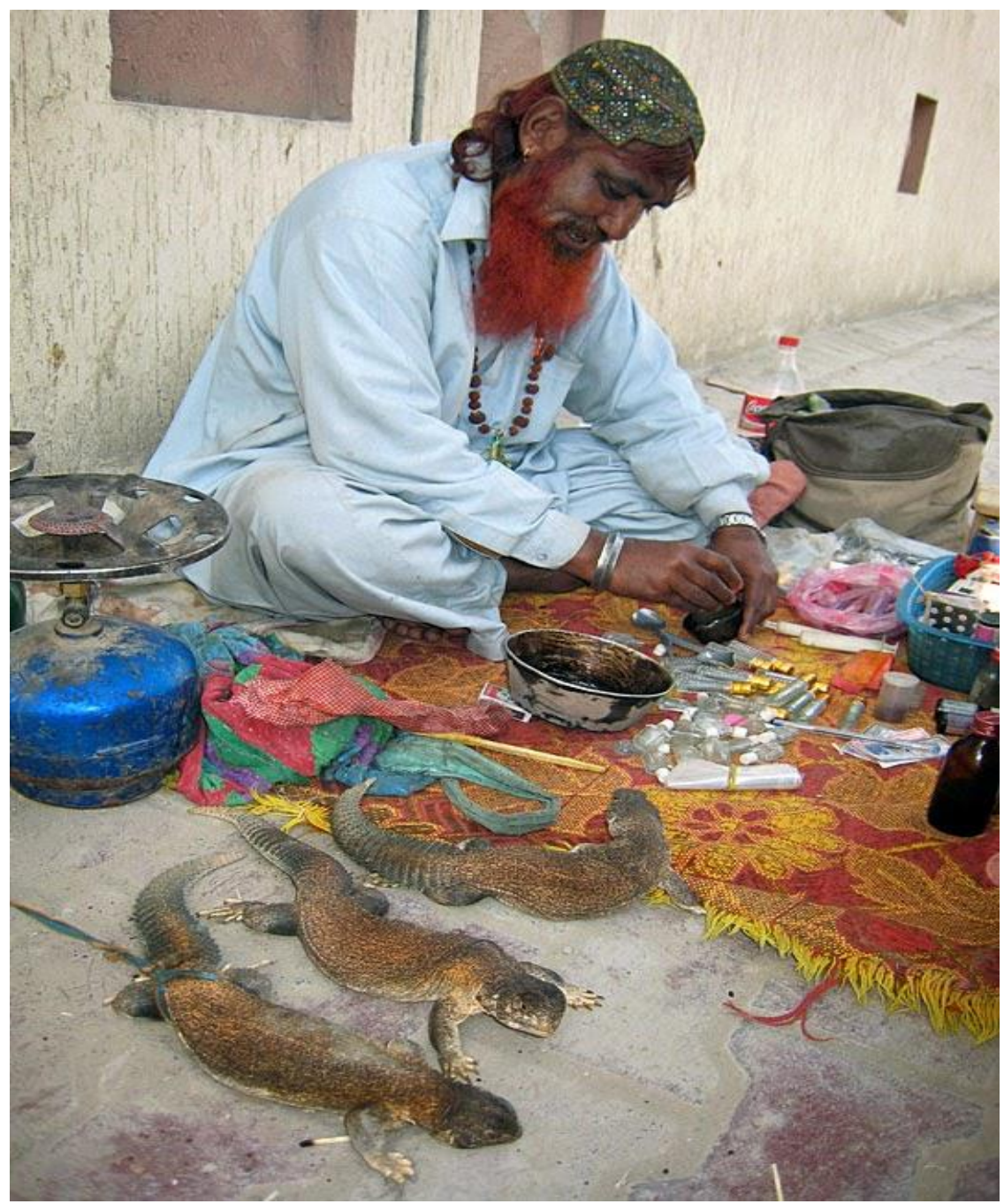

Footpath Hakeem extracting Sanda Oil 
As far back as the advancement of humanity, the penis has been viewed as the most vital part of a male body which is in charge of proliferation. A solid and solid penis is coveted by each man. If a man has an immature penis or on the off chance that it doesn't work legitimately while having intercourse the individual may fall into misery and despicable feeling about himself. The weakness and discouragement that emerges in the individual having a little or immature penis execute the internal identity certainty, and the individual may, get to be feeble. This may intensify the mental state of the man and he may at last commit suicide. So, people captured by so-called Hakeems.

\section{About SANDA (SAara HardWICKII)}

Sanda (Saara hardwickii), commonly known as Hardwicke's spiny-tailed lizard or the Indian spiny-tailed lizard is a species of agamid lizard found patchily distributed in the Thar desert, Kutch, and surrounding arid zones in India and Pakistan.

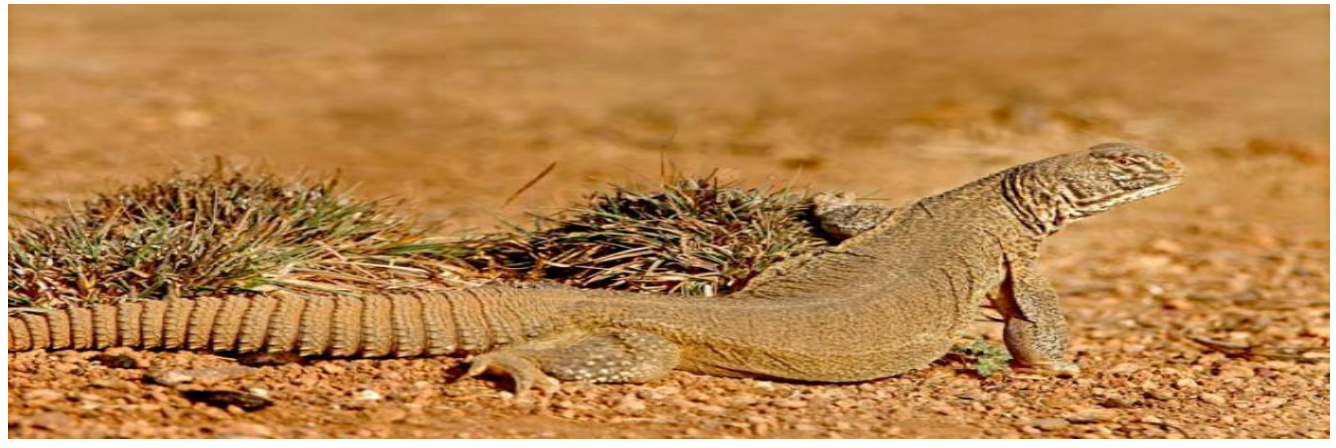

There can be seen a large number of so-called Hakeems in every city of Pakistan and India. Who claim for penis enlargement with so-called medicine named Sandy ka tail (Saara hardwickii oil).

The majority of the people who confuse about their actual penis size ask to Footpath Hakeems.

- Don't get erection regardless of the possibility that I have a powerful urge for sex.

- On the off chance that at any rate, I get the erection it is not completely erect.

- During intercourse, the penis gets considerably milder as in normal.

- I move erection when it's to discharge.

- Semen is not really a drop in some cases not by any means that.

- Last and last my penis in width is much more slender as it ought to be.

- It will be ideal if you recommend me what should I do I completely depressed.

- Anxiety and stress related to sex,

- Low body image and lack of self-confidence,

- Low libido due to stress and poor body image,

- Relationship problems due to lack of sexual activity,

- Erectile dysfunction,

- Premature ejaculation,

- Weak erections,

- Overall dissatisfaction with your sexual life. 


\section{Penis Analyzed by Hakeem Naseer before use of Sanda Oil (SaAra HARDWICKII OIL) AND AFTER THE USE OF SANDA OIL}

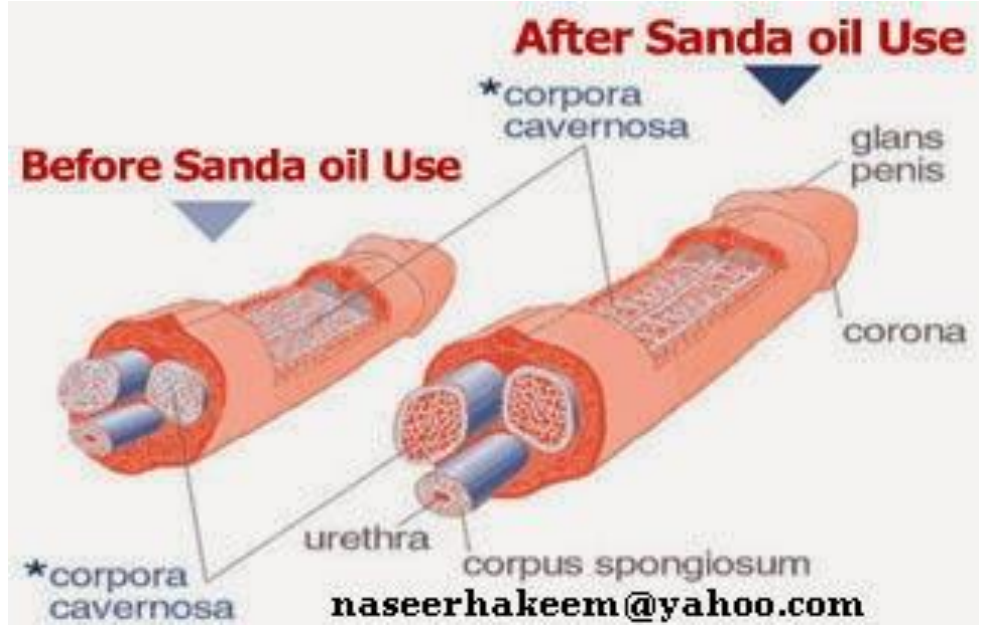

Sanda Oil (Saara hardwickii oil) is the most popular brand in Asian nations like India and Pakistan, and it is renowned for penis enlargement. So now we will examine its adequacy. I know would you need to realize that is there any genuine advantages of this oil?. The majority of the general populations are the desire to augment their penis estimate yet it is truly a truth that penis size does not make a difference for females' fulfillment. You require no less than 4 inches least keeping in mind the end goal to get excitement for ladies. Also, Women require a decent time for sex play, shake strong hard erections for satisfaction and a cherishing accomplice. However there are a couple of women who covet expansive penis size as they lean toward larger penis contrast with little. The straightforward case of this matter resemble a bosom size of ladies the same number of male does not make a difference with the extent of bosom, and they just get a kick out of the chance to intercourse in vagina opening, yet numerous guys have to ask for the greater bosom size of their female accomplices. Well, there is no demonstrated study have demonstrated that Sanda oil (Saara hardwickii oil) can broaden the span of a penis. This is a creature called Sanda (Saara hardwickii) which looks like green reptile lives in sand of desert, and the oil can be made by copying meat of Sanda. This creature lives in abandon and exceptionally hot in nature, so it is utilized for penis rub. Well, there is no assurance that it can grow the extent of a penis, in some cases, it might work or at times doesn't work yet it subjective property has loads of different advantages when it is connected for penis rubs.

To wrap things up, the most concerning issue of a little penis isn't the penis itself. However, fellow appended to it. Each penis is distinctive and exceptional, you can have an awesome and sexually satisfied life regardless of the possibility that your size is underneath normal. Continuously remember that the larger part of sexual incitement woman feels amid intercourse originates from her clit, not her vagina. Moreover, there is a great deal more about being a man than the measure of what you are bearing between your legs. That is presumably the most vital and significant counsel we can offer: Try to unwind, an extensive penis doesn't consequently or mystically make you more joyful or more charming for ladies. Try not to give your penis a chance to size control your selfregard. 


\section{REFERENCES}

Aremu, M., \& Akinwumi, O. (2014). Extraction, Compositional and Physicochemical Characteristics of Cashew (Anarcadium occidentale) Nuts Reject Oil. Asian Journal Of Applied Science And Engineering, 3(2), 227-234.

Babatunde, A., Kasim, L., \& Ayoade, A. (2015). Antimicrobial Study of Oil and Stem Bark Extracts of Pentaclethra Macrophylla Benth on Six Selected Pathogens. Malaysian Journal of Medical and Biological Research, 2(2), 71-74. Retrieved from http://iproclaim.my/archive/index.php/mjmbr/article/view/34

Hossain, N., \& Jalil, R. (2015). Sugar and Bioethanol Production from Oil Palm Trunk (OPT). Asia Pacific Journal Of Energy And Environment, 2(2), 81-84.

Nahar, K. (2015). Castor Bean (Ricinus communis L.) - A Biofuel Plant: Morphological and Physiological Parameters Propagated from Seeds in Bangladesh. Asian Business Review, 2(2), 6466. doi: http://dx.doi.org/10.18034/abr.v2i2.306

Olufemi, B., Jimoda, L., \& Agbodike, N. (2014). Adsorption of Crude Oil using Meshed Corncobs. Asian Journal Of Applied Science And Engineering, 3(1), 63-75.

Sultana, N., \& Tania, F. (2015). Effectiveness of Community Clinic in Urban Area: A Cross Sectional Study. Malaysian Journal of Medical and Biological Research, 2(1), 43-48. Retrieved from http://iproclaim.my/archive/index.php/mjmbr/article/view/56

Zahan, N. (2014). Factors Influencing Women's Reproductive Health. ABC Journal of Advanced Research, 3(2), 105-114. Retrieved from http://iproclaim.my/archive/index.php/abcjar/article/view/191

Publish Online and Print Version Both

Online ISSN: 2312-2021

Google Scholar: https://goo.gl/eozEWi 